\title{
Infecção toxoplásmica causa hipertrofia da parede do cólon de frangos
}

\author{
[Toxoplasmic infecction causes hipertrophy of the chicken colon wall] \\ C.F. Braga ${ }^{1}$, A.V. Silva ${ }^{2}$, D.M.G. Sant'Ana ${ }^{1}$, E.J.A. Araújo ${ }^{1 *}$ \\ ${ }^{1}$ Laboratório de Neurogastroenterologia Experimental - UNIPAR - Umuarama, PR \\ ${ }^{2}$ Laboratório de Medicina Veterinária Preventiva e Saúde Pública - UNIPAR - Umuarama,PR
}

\begin{abstract}
RESUMO
Estudaram-se os efeitos da infecção toxoplásmica sobre a morfometria da parede intestinal, a distribuição de fibras colágenas e a dinâmica de mucinas secretadas no cólon de frangos. Foram utilizados 16 frangos machos de linhagem comercial, com 26 dias de idade. As aves foram distribuídas, aleatoriamente, em três grupos (G). As do G1 não receberam inóculo e se caracterizaram como grupo-controle; nas do G2, foram inoculados cistos teciduais da cepa ME49 de Toxoplasma gondii; e nos G3, oocistos da cepa M7741 de $T$. gondii. Após 60 dias da inoculação, os animais foram sacrificados para coleta do cólon, o qual foi submetido à rotina de processamento histológico. Em G2 e G3, observou-se hipertrofia da parede do cólon, contudo não houve alteração na proporção do número de células caliciformes e de enterócitos presentes no epitélio intestinal.
\end{abstract}

Palavras-chave: aves, toxoplasmose, intestino grosso

\begin{abstract}
The effects of toxoplasmosis on the intestinal wall morphometry, the distribution of collagen fibers, and the dynamic of mucins secreted in the chicken colon were analyzed. Sixteen 26-day-old male Cobb chicks (Gallus gallus) were randomly distributed into three groups (G1, G2, and G3). G1 received no inoculums and characterized the control group, G2 was inoculated with tissue cysts of ME49 strain of Toxoplasma gondii, and G3 was inoculated with oocytes of M7741 strain of T. gondii. After 60 days of inoculation, the animals were slaughtered and had their colon collected and submitted to histological processing. Transversal cuts $(4 \mu \mathrm{m})$ were stained with Hematoxylin-Eosin (HE), Periodic Acid Schiff (PAS), Alcian Blue pH 2.5, Alcian Blue (AB) pH 1.0, and Azan. G2 and G3 animals showed hypertrophy of the colon wall, but the proportion between the number of goblet cells and enterocytes present in the intestinal epithelium was not altered.
\end{abstract}

Keywords: birds, toxoplasmosis, bowel intestine

\section{INTRODUÇÃO}

A toxoplasmose é uma zoonose com grande disseminação geográfica, causada por um protozoário denominado Toxoplasma gondii. É um parasito intracelular obrigatório, de ciclo de vida heteroxeno, que se caracteriza por uma ampla diversidade de hospedeiros, incluindo somente felídeos como hospedeiros definitivos e várias espécies de mamíferos e de aves como intermediários. Os animais infectam-se, principalmente, por ingestão de água ou alimentos contaminados com oocistos, ou pelo consumo de carne crua ou malcozida, contendo cistos teciduais, os quais geralmente estão repletos de bradizoítos (Weiss e Kim, 2007). Vale destacar que as aves se infectam quando ingerem oocistos presentes no solo, alimento e água contaminados, por isso são vistas como importantes marcadores ambientais da disseminação de T. gondii (Dubey et al., 2006; Galli et al., 2008).

Recebido em 23 de dezembro de 2009

Aceito em 25 de fevereiro de 2011

*Autor para correspondência (corresponding author)

E-mail: eduardoaraujo@unipar.br 
Como esse parasito penetra no hospedeiro pelo tubo digestório, um recente estudo demonstrou que quase todas as espécies hospedeiras desenvolvem alterações da parede intestinal quando se infectam com T. gondii (Schreiner e Liesenfeld, 2009). No entanto, poucos são os estudos que avaliaram a parede intestinal das aves, e a maioria realizou apenas análises descritivas (Howerth e Rodenrth, 1985; Work et al., 2002; Dubey et al., 1994; Dubey e Hamir, 2002; Hartley et al., 2008). Há somente dois estudos disponíveis na literatura consultada, nos quais se avaliaram as alterações histomorfométricas e de marcações histoquímicas da parede intestinal de aves infectadas com $T$. gondii, porém ambos se referem a segmentos do intestino delgado: duodeno (Bonapaz et al., 2010) e íleo (Shiraishi et al., 2009). Em razão do exposto, o objetivo deste trabalho foi estudar a morfometria da parede intestinal e a proporção de células caliciformes e de enterócitos presentes no epitélio do cólon de frangos domésticos infectados com T. gondii.

\section{MATERIAL E MÉTODOS}

O protocolo experimental deste estudo foi previamente aprovado pelo Comitê de Ética em Pesquisa Envolvendo Experimentação Animal da Universidade Paranaense (Protocolo $\left.n^{\circ} 10161 / 2007\right)$.

Foram utilizados 16 frangos da linhagem Cobb, com 26 dias de idade (1571,25 $\pm 127,38 g$ ), os quais foram adquiridos de um criatório comercial. Antes de serem inoculados, os animais passaram por um período de adaptação ao ambiente por 10 dias, período em que foi coletado sangue pela punção da veia cefálica, visando à detecção de anticorpos séricos (IgG) anti-T.gondii, pelo método de aglutinação direta. Somente animais com resultados negativos participaram deste estudo. Durante todo o experimento, as aves foram mantidas em gaiolas apropriadas e alojadas no aviário do hospital veterinário escola.

As aves foram distribuídas aleatoriamente em três grupos (G1, G2 e G3), identificadas com anilha e tratadas com ração comercial COCARI ${ }^{\circledR}$ e água ad libitum. No $\mathrm{G} 1$, as aves $(\mathrm{n}=4)$ foram mantidas como controle, portanto não receberam inóculo. No G2, as aves $(\mathrm{n}=6)$ receberam, pela via oral, $1 \mathrm{~mL}$ de suspensão contendo $2 \times 10^{2}$ cistos teciduais da cepa ME49 de Toxoplasma gondii (genótipo II). No G3, as aves $(n=6)$ receberam, pela via oral, $1 \mathrm{~mL}$ de suspensão contendo $10^{3}$ oocistos da cepa M7741 de Toxoplasma gondii (genótipo III).

Após 60 dias da inoculação, os animais foram mortos por deslocamento craniocervical. Coletou-se sangue para verificação da ausência ou presença de IgG anti-T.gondii por intermédio da técnica de aglutinação direta, considerando-se como positivos títulos acima de 25. Em seguida, realizou-se a laparotomia para coleta do cólon, o qual foi avaliado quanto à presença de lesões macroscópicas e, na sequência, lavado com solução de $\mathrm{NaCl}$ a $0,9 \%$ e fixado em solução de Bouim, durante quatro horas. Esses segmentos intestinais foram desidratados em séries ascendentes de álcool etílico, diafanizados em xilol e incluídos em parafina. Cortes transversais de $4 \mu \mathrm{m}$ foram corados com hematoxilina-eosina (HE); Azan - para análise da distribuição de fibras colágenas -; periodic acid schiff (PAS) para detecção de mucinas neutras -; alcian blue (AB) $\mathrm{pH}$ 2,5 - para detecção de sialomucinas e sulfomucinas -; e alcian blue (AB) $\mathrm{pH}$ 1,0 - para detecção de sulfomucinas -, seguindo protocolo descrito por Myers et al. (2008). No caso das técnicas para detecção de glicoconjugados - PAS e $\mathrm{AB}-$, realizou-se contracoloração com hematoxilina.

Inicialmente foi realizada uma avaliação qualitativa da parede intestinal, utilizando-se lâminas coradas com HE, Azan e PAS. No primeiro caso, observou-se a organização dos tecidos que compõem os diferentes estratos da parede intestinal, bem como se procurou identificar cistos teciduais de $T$. gondii; no segundo, analisou-se a distribuição de fibras colágenas dentro e entre os estratos da parede do cólon; e no terceiro, também foi investigada a presença de cistos teciduais, pois a parede elástica dessa estrutura contém glicoconjugados neutros.

A análise morfométrica da parede intestinal foi realizada a partir de imagens de cortes corados com HE capturadas por intermédio de uma câmera digital (Moticam 2000, 2.0 Megapixel) acoplada a um microscópio de luz trinocular (MOTIC B5). Imagens capturadas com a 
objetiva de $4 \mathrm{X}$ foram utilizadas para medir a espessura total da parede e da túnica muscular; com a objetiva de $10 \mathrm{X}$, mediu-se a espessura da túnica mucosa, e com a de $40 \mathrm{X}$, mensurou-se a espessura da túnica muscular da mucosa e da tela submucosa. Foram realizadas 80 medidas de cada estrutura, distribuídas uniformemente em toda a circunferência intestinal de cada frango.

Quantificou-se também o número de células caliciformes e enterócitos em $0,21 \mathrm{~mm}^{2}$ de túnica mucosa por animal. Em seguida, calculou-se a proporção entre o número de células caliciformes e o número de enterócitos. Essa análise foi realizada com as lâminas submetidas às técnicas histoquímicas para detecção de glicoconjugados (PAS, AB pH 2,5 e AB pH 1,0).

Os dados foram submetidos ao teste estatístico D’Agostino Pearson para se verificar o tipo de distribuição. Dados com distribuição normal foram apresentados como média \pm desvio-padrão, e para a comparação entre os grupos (G2xG1 e G3xG1), utilizou-se teste $\mathrm{t}$ para amostras independentes. Dados com distribuição livre foram apresentados como mediana - percentil 25 e percentil 75 -, e utilizou-se o teste de MannWhitney para comparação entre os grupos (G2xG1 e G3xG1). Em todos os testes estatísticos, valores de P menores que 0,05 foram considerados significantes.

\section{RESULTADOS E DISCUSSÃO}

Mediante a análise sorológica, constatou-se que os frangos do G2 e G3 tiveram resultado positivo para a presença de IgG contra T. gondii, e os do G1 permaneceram com resultado negativo. Em estudo paralelo com animais do G2 e G3 deste estudo (Galli et al., 2008), realizou-se o reisolamento do parasito a partir do pool de cérebro e coração de cada animal inoculando-o em camundongos (quatro para cada frango). Em cinco animais do G2 e em quatro do G3, o parasita foi reisolado, o que é indicativo de que cistos teciduais foram formados tanto nos frangos infectados com a cepa genótipo II quanto naqueles infectados com a cepa genótipo III. Isto se confirma pelo fato de ter sido encontrado um cisto tecidual na tela submucosa de um dos animais do G2 (Fig. 1). Ressalta-se, ainda, que os cistos teciduais correspondem à forma de vida de T. gondii que lhe permite escapar do sistema imune e permanecer no hospedeiro. Portanto, teoricamente, cistos teciduais podem ser formados em quaisquer células do hospedeiro definitivo ou intermediário, porém o parasito apresenta maior tropismo para alguns tecidos. Nesse caso, destaca-se o tecido nervoso e o muscular. Por isso, é comum observar a presença de cistos teciduais no cérebro e coração de animais infectados por este protozoário (Suzuki et al., 2007).

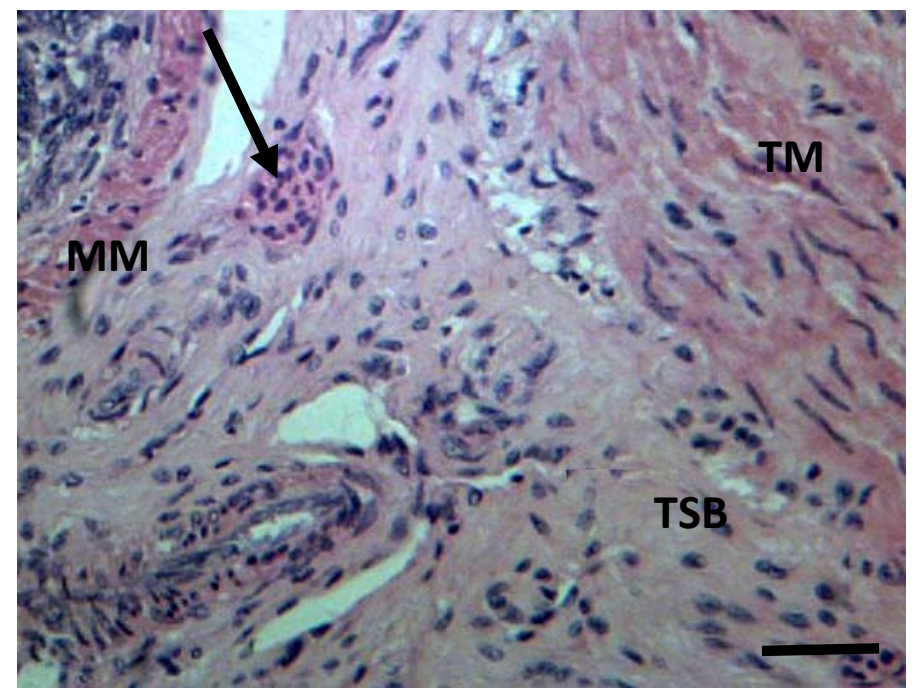

Figura 1. Fotomicrografia de cisto tecidual (seta) presente na tela submucosa de um dos frangos do grupo infectado com uma cepa genótipo II (ME-49) de Toxoplasma gondii. MM: muscular da mucosa; TSB: tela submucosa; TM: túnica muscular. H.E. Barra: $10 \mu \mathrm{m}$. 
Poucos são os trabalhos que relataram a presença de cistos teciduais no intestino (Dubey et al., 1988). Dessa forma, o resultado sorológico e o de reisolamento do parasito confirmam que os animais do G2 e G3 realmente foram infectados por $T$. gondii e indicam que a infecção já tinha atingido o seu estágio crônico, fato esperado, pois já havia passado 60 dias após a inoculação. Assim, considera-se que as alterações - que serão descritas e discutidas - no cólon dos animais do G2 e G3 em relação aos do G1 foram desencadeadas pela infecção toxoplásmica.

Na análise qualitativa dos cortes histológicos, observou-se que a parede do cólon dos animais do G2 e G3 apresentava espessura maior que a do G1, fato confirmado por meio da análise morfométrica. Constatou-se, ainda, que, nos animais do G2, a tela submucosa projetava-se em direção à mucosa em maior quantidade e intensidade que a do G1. Os cortes corados com Azan demonstraram maior quantidade de fibras colágenas nessas regiões. Nos animais do G3, essa característica não foi observada.

Quanto à mucosa, nas aves do G1, foi comum observar nódulos linfoides, mas, nos animais do G2, observou-se tendência de hiperplasia dentro dessas estruturas, o que possivelmente contribuiu para a impressão de que esses nódulos ocupavam maior área da mucosa, fato observado em menor intensidade nas aves do G3. Além disso, vilos intestinais também foram observados na mucosa de todos os animais, sem nenhuma alteração aparente. É muito comum a presença de vilos esparsos e de diferentes altura e espessura no cólon de aves (Bacha e Bacha, 2003). Nenhum dos cólons coletados apresentou lesões com características hemorrágica ou de necrose, e observou-se em um dos frangos do G3 a presença de megacólon.

Na Tab. 1 encontram-se os resultados relacionados à análise morfométrica dos cortes histológicos dos cólons coletados. Em geral, percebe-se que a infecção toxoplásmica causou hipertrofia da parede do cólon tanto nos animais do G2 - 52,4\% - como nos do G3 - 58,6\% quando comparados aos do G1 $(\mathrm{P}<0,001)$. Notase ainda que esse aumento da parede intestinal foi provocado, principalmente, por ampliação da túnica muscular. Também contribuíram para essa hipertrofia: a tela submucosa, a muscular da mucosa e a túnica mucosa. Contudo, é importante destacar que tanto a cepa genótipo II como a III provocaram reações morfométricas semelhantes no cólon, ou seja, provavelmente desencadearam maior proliferação celular e/ou maior recrutamento de células do sistema imune.

Tabela 1. Mediana percentil (25); percentil (75) da espessura da parede total, da túnica muscular, da muscular da mucosa e da túnica mucosa do cólon de frangos infectados por Toxoplasma gondii

\begin{tabular}{lccc}
\multicolumn{1}{c}{ Parâmetro $(\mu \mathrm{m})$} & $\mathrm{G} 1$ & $\mathrm{G} 2$ & $\mathrm{G} 3$ \\
\hline Parede total & $751,2(630,3 ; 901,4)$ & $1145,1^{*}(992,6 ; 1399,4)$ & $1191,1^{*}(900,0 ; 1519,4)$ \\
Túnica muscular & $429,5(329,0 ; 600,1)$ & $772,9^{*}(587,7 ; 902,7)$ & $689,5^{*}(547,8 ; 803,5)$ \\
Tela submucosa & $29,0(25,0 ; 34,0)$ & $66,0^{*}(48,0 ; 100,0)$ & $59,0^{*}(46,0 ; 80,0)$ \\
Muscular da mucosa & $24,4(20,7 ; 31,8)$ & $28,6^{*}(23,0 ; 34,5)$ & $25,3^{*}(21,2 ; 31,1)$ \\
Túnica mucosa & $339,9(266,8 ; 429,6)$ & $474,0^{*}(388,9 ; 553,1)$ & $476,1^{*}(394,8 ; 542,9)$ \\
\hline
\end{tabular}

Valores expressos como mediana (P25; P75). G1: grupo-controle; G2: grupo infectado por cistos teciduais da cepa ME49 de T. gondii (genótipo II); G3: grupo infectado por oocistos da cepa M7741 de T. gondii (genótipo III). Medianas marcadas com asteriscos no G2 e G3 indicam diferença significativa em relação ao G1 (P<0,001).

Neste sentido, sabe-se que a homeostase intestinal é coordenada por respostas de diferentes tipos celulares, incluindo células do sistema imune e de outros sistemas. A interação entre essas células é ampliada durante a inflamação, aumentando a exposição das células receptoras a mediadores solúveis, tais como citocinas, secretadas por células imunes. A ação dessas citocinas pode alterar o metabolismo das células da parede intestinal, deixando-as hiper ou hipotróficas, dependendo do tipo de infecção e da intensidade da inflamação (Mawe et al., 2004). Considerando-se que T. gondii inoculado pela via oral causa um processo inflamatório na parede intestinal (Weiss e Kim, 2007; Schreiner e Liesenfeld, 2009), considera-se que esta seja a principal explicação para o aumento da espessura da parede total do cólon, observado nos animais infectados neste estudo.

Resultado antagônico foi observado em um estudo paralelo (mesmas aves) com o duodeno 
dos animais do G3, no qual se observou redução de 27,4\% da parede deste órgão (Bonapaz et al., 2010), e um outro estudo (mesmas aves) com o íleo, no qual a parede intestinal aumentou 20,3\% nos animais do G2 e diminuiu 12,0\% nos do G3 (Shiraishi et al., 2009). Dessa forma, fica evidente que cada segmento do tubo digestório reage de forma diferente à infecção causada por T. gondii.Houve aumento da espessura da túnica muscular do cólon dos animais do G2 e do G3, $80,0 \%$ e $60,5 \%$, respectivamente, quando comparada à do $\mathrm{G} 1(\mathrm{P}<0,0001)$, o que demonstra que tanto a cepa genótipo II quanto a genótipo III de $T$. gondii, provavelmente, desencadearam sérias alterações no sistema de controle do funcionamento das células musculares lisas, presentes neste estrato da parede intestinal, provocando hiperplasia e/ou hipertrofia celular.

Neste contexto, é importante destacar que macrófagos presentes na túnica muscular são os primeiros a conduzir os efeitos inflamatórios e responder a eles, após contato com endotoxinas secretadas por microrganismos, ativando a musculatura lisa, no intuito de conduzi-la a um estado de hipercontratibilidade para expulsão do parasito (Bauer, 2008). Além disso, é importante recordar que a túnica muscular do intestino é formada por duas camadas de tecido muscular liso: uma mais interna, com células dispostas circularmente à luz intestinal, e outra mais externa, contendo células dispostas longitudinalmente. Entre essas duas camadas de músculo liso, encontra-se um grupo muito numeroso de neurônios ganglionados, o qual forma o plexo mientérico (ou de Auerbach), que é o principal suprimento nervoso intrínseco da túnica muscular (Furness, 2006). Dessa forma, é possível considerar que a infecção toxoplásmica pode ter alterado o equilíbrio de comunicações entre células do sistema imune - neurônios mientéricos - células musculares lisas. Assim, o aumento expressivo da espessura da túnica muscular dos animais infectados com T. gondii, observado neste estudo, pode ter ocorrido em função de respostas tanto advindas do sistema imune como dos neurônios mientéricos.

Estudos paralelos com os animais do G3 verificaram atrofia de $20,5 \%$ da túnica muscular no duodeno (Bonapaz et al., 2010), enquanto no íleo nenhuma alteração foi observada (Shiraishi et al., 2009). Nos animais do G2, observou-se aumento de 3,3\% deste estrato no íleo (Shiraishi et al., 2009). Ainda em estudos paralelos, destaca-se que a infecção toxoplásmica nas aves do G3 provocou morte de cerca de $70 \%$ dos neurônios mientéricos duodenais (Bonapaz et al., 2010), o que pode ter contribuído para a referida atrofia da túnica muscular nesse órgão. Mais estudos que avaliem o plexo mientérico de frangos infectados com $T$. gondii devem ser realizados, em razão das alterações morfológicas que ocorrem na túnica muscular e, também, porque foi observada intensa diarreia nos animais infectados neste experimento.

A tela submucosa geralmente é formada por um tecido conjuntivo denso, caracterizado por um número menor de células e intensa presença de fibras colágenas e elásticas (Junqueira e Carneiro, 2008). Observou-se, neste estudo, que a espessura dessa camada foi a que mais sofreu alterações por causa da infecção toxoplásmica, visto que, nos animais do G2, houve aumento de $127,6 \%$, e nos do $\mathrm{G} 3$, de $103,4 \%(\mathrm{P}<0,001)$.

Como neste estrato há uma rica vascularização, pode-se considerar natural que muitos leucócitos sofreram diapedese nesta área para ocupar essa região, o que explicaria o aumento observado. No entanto, no estágio avaliado - 60 dias após a inoculação -, esta área estava ocupada principalmente por fibroblastos. Isso permite inferir duas possibilidades não excludentes: 1) houve reação inflamatória que causou lesões teciduais as quais, no entanto, já estavam no estágio de cicatrização; 2) houve aumento do número de fibroblastos no intuito de deixar esta área mais densa em fibras, sobretudo colágenas, a fim intuito de dar mais resistência à parede intestinal e também manter o elo entre a túnica mucosa e a túnica muscular. Essas sugestões se apoiam no fato de que, tanto nos animais do G2 como nos do G3, houve aumento da espessura da túnica mucosa e de que também foi observada maior quantidade de fibras colágenas coradas com técnica de Azan nesta área.

O aumento mais expressivo da espessura da tela submucosa nos animais do G2 talvez esteja relacionado ao maior número de projeções deste estrato em direção à túnica mucosa. Além disso, é importante lembrar que o cisto observado e registrado neste estudo foi encontrado na tela submucosa em um dos animais do G2. Vale também destacar que, na tela submucosa, há um grupo ganglionado de neurônios, denominado de 
plexo submucoso (ou de Meissner), o que está envolvido no controle do fluxo sanguíneo tanto na tela submucosa como na túnica mucosa, e no controle de secreções das glândulas intestinais, no caso do cólon - glândulas de Lieberkühn. Dessa forma, sugere-se que este grupo de neurônios possa ter sofrido alterações durante a infecção toxoplásmica e que este aspecto deve ser objeto de estudo para futuras investigações. Todavia, não há relatos na literatura de alterações morfométricas da tela submucosa de aves infectadas com T. gondii.

Separando a tela submucosa da túnica mucosa, há um grupo de células musculares lisas que também forma dois feixes, semelhantemente ao descrito para a túnica muscular. Essas células formam a muscular da mucosa, responsável por realizar movimentos da mucosa que contribuem para aumentar ou diminuir o contato da mucosa com a luz intestinal. Observou-se, neste estudo, que a espessura da muscular da mucosa aumentou 17,2\% no cólon dos animais do G2 e $3,7 \%$ no dos G3 em relação aos do G1 $(\mathrm{P}<0,001)$. Resultado semelhante foi encontrado no íleo das mesmas aves utilizadas neste estudo, o qual demonstrou aumento de 30,5\% nas aves do G2, e nenhuma alteração nas do G3 (Shiraishi et al., 2009).

No duodeno, a muscular da mucosa sofreu uma atrofia de 27,9\% nos animais do G3 (Bonapaz et al., 2010). Esse fato indica que, para a muscular da mucosa, a cepa genótipo II de $T$. gondii utilizada neste estudo provocou alterações similares entre a porção final do intestino delgado e o intestino grosso, enquanto a cepa genótipo III causou intensas modificações apenas na porção inicial do intestino delgado. Esses achados são coerentes com o fato de que a muscular da mucosa dos animais do G2 pode apresentar maior capacidade de realizar tração, pois foi visível o aumento de nódulos linfoides presentes na mucosa desses animais.

Desse modo, a análise dos estratos da parede intestinal do cólon realizada neste estudo demonstrou que a túnica mucosa aumentou aproximadamente $40,0 \%$ tanto nos animais do G2 como nos animais do G3, quando comparados aos do $\mathrm{G} 1(\mathrm{P}<0,001)$. Estes achados apontam, mais uma vez, que tanto a cepa genótipo II como a III provocaram reações morfométricas semelhantes no cólon, diferentemente do observado em estudo paralelo com o íleo desses mesmos animais, o qual demonstrou aumento de 48,3\% da túnica mucosa nos animais do G2 e redução de 7,8\% nos do G3 (Shiraishi et al., 2009).

Em estudos paralelos, a cepa genótipo III de $T$. gondii, utilizada neste estudo, causou atrofia da mucosa no intestino delgado (Bonapaz et al., 2010; Shiraishi et al., 2009) e hipertrofia no intestino grosso, enquanto a cepa genótipo II causou hipertrofia desta camada tanto na porção final do intestino delgado (Shiraishi et al., 2009) como no intestino grosso. O recrutamento de células do sistema imune para a túnica mucosa pode ser uma explicação para o aumento dessa camada observado nos animais infectados com $T$. gondii deste estudo. Neste sentido, cabe destacar que, em animais inoculados, pela via oral, com cistos teciduais ou oocistos de $T$. gondii, os zoítos liberados no lúmen do intestino delgado invadem enterócitos ou linfócitos intraepiteliais e alcançam a lâmina própria, onde se diferenciam em taquizoítos e invadem células presentes neste local. Quando taquizoítos interagem com mastócitos presentes na lâmina própria, desencadeia-se um processo de quimiotaxia para neutrófilos, macrófagos e linfócitos (Ferreira et al., 2004). Essas células também são atraídas por moléculas secretadas por enterócitos presentes na região basolateral das criptas intestinais (Kasper et al., 2004). Este pode ser considerado um processo chave para contenção do parasito, já que se sabe que a depleção de neutrófilos em camundongos diminui a resistência do organismo à infecção causada por T. gondii (Bliss et al., 2001).

Neste estudo, observou-se a proporção do número de células caliciformes e enterócitos presentes no epitélio intestinal (Tab. 2), e constatou-se que a infecção causada pelas duas cepas de $T$. gondii não alterou essa proporção, isto é, o perfil secretório de mucinas no cólon dos animais do G2 e do G3 não foi modificado. Essas mucinas compõem o muco que recobre o epitélio intestinal no intuito de protegê-lo contra agressores químicos, físicos e biológicos, que podem estar presentes na luz intestinal. Dependendo da composição de seus monossacarídeos, as mucinas são classificadas em neutros e subtipos ácidos: não sulfatadas (sialomucinas) e sulfatadas (sulfomucinas), consideradas significativamente mais ácidas 
(Myers et al., 2008). Por isso, neste estudo, foram utilizadas três técnicas histoquímicas para evidenciação de glicoconjugados (PAS, $\mathrm{AB} \mathrm{pH}$ 2,5 e $\mathrm{AB} \mathrm{pH} 1,0$ ), a fim de se perceber se a infecção toxoplásmica alteraria o perfil secretório de um desses tipos de mucinas, porém, no cólon, não houve nenhuma alteração significativa. No duodeno dos animais do G3, houve aumento de secreção de mucinas neutras (PAS-reativas) e sulfomucinas (AB $\mathrm{pH}$ 1,0reativas), enquanto no íleo tanto a cepa genótipo II como a genótipo III induziram ao aumento da secreção de mucinas neutras. O fato de o perfil secretório de mucinas não ter sido alterado no cólon indica que o muco que cobria o epitélio desse órgão estava cumprindo seu papel a contento, talvez porque esses animais estavam com diarreia e, por causa disso, havia maior quantidade de água na luz intestinal, o que fazia com que a abrasão das fezes com a superfície interna do cólon estivesse menor, não necessitando de uma camada de muco mais densa. Vale ainda destacar que células caliciformes tanto do intestino (Speer e Dubey et al., 1998) como da conjuntiva (Skorich et al., 1988) podem ser infectadas por T. gondii.

Tabela 2. Média \pm desvio-padrão da proporção do número de células caliciformes e enterócitos evidenciadas por técnicas histoquímicas para glicoconjugados em uma área de $0,21 \mathrm{~mm}^{2}$ de túnica mucosa do cólon de frangos infectados por Toxoplasma gondii

\begin{tabular}{cccc}
\hline Técnica & G1 & G2 & G3 \\
\hline PAS & $0,59 \pm 0,16$ & $0,48 \pm 0,09$ & $0,55 \pm 0,04$ \\
AB pH 2,5 & $0,52 \pm 0,03$ & $0,52 \pm 0,09$ & $0,62 \pm 0,12$ \\
A.B pH 1,0 & $0,57 \pm 0,06$ & $0,49 \pm 0,12$ & $0,57 \pm 0,08$ \\
\hline
\end{tabular}

P.A.S: periodic-acid-schiff; AB: alcian blue. Valores expressos como média \pm desvio-padrão. G1: grupo-controle; G2: grupo infectado por cistos teciduais da cepa ME49 de T. gondii (genótipo II); G3: grupo infectado por oocistos da cepa M7741 de T. gondii (genótipo III). Não houve diferença significativa entre os grupos para nenhuma das técnicas.

Dessa forma, conclui-se que a infecção, durante 60 dias, causada por cistos teciduais de uma cepa genótipo II de T. gondii, assim como por oocistos de uma cepa genótipo III deste mesmo parasito provoca hipertrofia da parede do cólon, contudo não altera a proporção do número de células caliciformes e de enterócitos presentes no epitélio intestinal.

\section{REFERÊNCIAS BIBLIOGRÁFICAS}

BACHA, W.J.; BACHA, L.M. Atlas colorido de histologia veterinária. São Paulo: Roca, 2003. 457p.

BAUER, A.J. Mentation on the immunological modulation of gastrintestinal motility. Neurogastroenterol. Motil., v.20, suppl.1, p.8190, 2008.

BLISS, S.K.; GAVRILESCU, L.C.; ALCARAZ, A. et al. Neutrophil depletion during Toxoplasma gondii infection leads to impaired imunity and lethal systemic pathology. Infect. Immun., v.69, p.4898-4905, 2001.

BONAPAZ, R.S.; HERMES-ULIANA, C.; SANTOS, F.N. et al. Efeitos da infecção por oocistos de Toxoplasma gondii sobre a parede intestinal e o plexo mientérico de Gallus gallus. Pesq. Vet. Bras., v.30, p.787-792, 2010.
DUBEY, J.P.; GENDRON-FITZPATRICK, A.P.; LENHARD, A.L. et al. Fatal toxoplasmosis and enteroepithelial stages of Toxoplasma gondii in a pallas cat (Felis manul). J. Protozool., v.35, p.528-530, 1988.

DUBEY, J.P.; GOODWIN, M.A.; RUFF, M.D. et al. Experimental toxoplasmosis in japanese quail. J. Vet. Diagn. Invest., v.6, p.216-221, 1994.

DUBEY, J.P.; HAMIR, A.N. Experimental Toxoplasmosis in Budgerigars (Melopsittacus undulates). J. Parasitol., v.88, p.514-519, 2002.

DUBEY, J.P.; VIANNA, M.C.; SOUSA, S. et al. Characterization of Toxoplasma gondii isolates in free-range chickens from Portugal. $J$. Parasitol., v.92, p.184-186, 2006.

FERREIRA, G.L.S.; MINEO, J.R.; OLIVEIRA, J.G. et al. Toxoplasma gondii and mast cell interactions in vivo and in vitro: Experimental infection approaches in Calomys callosus (Rodentia, Cricetidae). Microb. Infect., v.6, p.172-181, 2004.

FURNESS, J.B. The enteric nervous system. Malden: Blackwell, 2006. cap.1, p.1-28. 
GALLI, S.; BELINATO, F.C.; LUCAS, T.M. et al. Infecção experimental de frangos domésticos (Gallus gallus) com cepas geneticamente distintas de Toxoplasma gondii. Vet. Zootec., v.15, p.542-550, 2008.

HARTLEY, J.; BOOTH, R.; SLOCOMBE, R.F. et al. Lethal Toxoplasmosis in an aviary of Kakarikis (Cyanoramphus spp.) in Australia. J. Parasitol., v.94, p.1424-1425, 2008.

HOWERTH, E.W.; RODENROTH, N. Fatal Systemic Toxoplasmosis in a Wild Turkey. $J$. Wild Dis., v.21, p.446-449, 1985.

JUNQUEIRA, L.C.; CARNEIRO, J. Histologia básica. 11.ed. Rio de Janeiro: Guanabara Koogan, 2008.

KASPER, L.; COURRET, N.; DARCHE, S. et al. Toxoplasma gondii and mucosal immunity. $J$. Parasitol., v.34, p.401-409, 2004.

MAWE, G.M.; COLLINS, S.M.; SHEADONOHUE, T. Changes in enteric neural circuitry and smooth muscle in the inflamed an infected gut. Neurogastroenterol. Motil., v.16, suppl.1, p.133-136, 2004.

MYERS, B.M. FREDENBURGH, J.L.; GRIZZLE, W.E. Carbohydrates. In: BANCROFT, J.D.; GAMBLE, M. (Eds). Theory and practice of histological techniques. 6.ed. Philadelphia: Elselvier, 2008. cap.11, p.161-187.

SCHREINER, M.; LIESENFELD, O. Small intestinal inflammation following oral infection with Toxoplasma gondii does not occur exclusively in C57BL/6 mice: review of 70 reports from the literature. Mem. Inst. Oswaldo Cruz, v.104, p.221-233, 2009.
SHIRAISHI, C.S.; AZEVEDO, J.F.; SILVA, A.V. et al. Análise morfométrica da parede intestinal e dinâmica de mucinas secretadas no íleo de frangos infectados por Toxoplasma gondii. Ciênc. Rural, v.39, p.2146-2153, 2009.

SKORICH, D.N.; CHIAPPINO, M.L.; NICHOLS, B.A. Invasion of the guinea pig conjunctiva by Toxoplasma gondii. Invest. Ophthalmol. Vis. Sci., v.29, p.1871-1880, 1988.

SPEER, C.A.; DUBEY, J.P. Ultrastructure of early stages of infections in mice fed Toxoplasma gondii oocysts. J. Parasitol., v.116, p.35-42, 1998.

SUZUKI, Y.; HALONEN, S.; WANG, X. et al. Cerebral toxoplasmosis: pathogenesis and host resistance. In: WEISS, L.; KIM, K. (Eds). Toxoplasma gondii: the model apicomplexan. Perspectives and methods. Rio de Janeiro: Elsevier, 2007. cap.21, p.567-591.

WEISS, L.; KIM, K. The ultrastructure of Toxoplasma gondii. In: WEISS, L.; KIM, K. Toxoplasma gondii: the model apicomplexan. Perspectives and methods. Rio de Janeiro: Elsevier, 2007. p.19-48.

WORK, T.M.; MASSEY, J.G.; LINDSAY, D.S. et al.Toxoplasmosis in three species of native and introduced hawaiian birds. J. Parasitol., v.88, p.1040-1042, 2002. 